\title{
No professorship: There is a normal, non-scary life outside academia
}

\author{
Liv Heinecke ${ }^{1,2}$, M. Chevalier ${ }^{3}$, K. Ashastina ${ }^{4,5}$ and J. Picas ${ }^{6}$
}

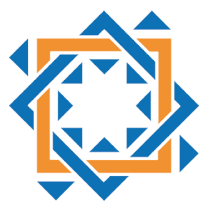

PAGES Morillo de Tou 2017

3rd Young Scientists Meeting

Global Challenges for our Common Future

a paleoscience perspective

In today's scientific world, the definition of a successful career is often associated with professorship. This goal is unfortunately only achieved by roughly $0.5-16 \%$ of those who pursue a PhD (https://lifesciencenetwork11. connectedcommunity.org/blogs/leah-cannon/2016/09/15/how-many-phd-graduatesbecome-professors).

While the percentage varies between scientific domains and countries, this apparent "limited success rate" is an important source of stress for many early-career researchers (ECRs), as illustrated by the vivid discussions that took place during the breakout group sessions organized during PAGES 3rd Young Scientists Meeting (YSM). While most participants acknowledged feeling - or having felt - this pressure, we all agreed that alternative ways outside academia can, and should, lead to equally successful careers. Unfortunately, we also came to the conclusion that our ideas of what these alternative ways might actually be were rather limited.

A large part of this stress or pressure comes from our limited perception of the "outside world". During the PhD, most of us live in an academic bubble. We become so focused on our daily tasks that we forget about the non-academic world and sometimes even convince ourselves that academia is our only viable option (Fig. 1). This psychological barrier stems from not only a lack of knowledge about other worthwhile job opportunities, but also the stigmatism of choosing what feels like a "second-class" career. A perfect illustration of this came during a YSM discussion about children's education. Although all members of the breakout group agreed that engaging children in environmental issues early on is critical to educate the next generation, it was also strikingly evident that leaving academia to become a teacher was perceived as a failure for most participants.

Most of us enjoy working in science because it is a challenging job, with short- and long-term objectives that necessitate a large spectrum of competences, such as using/ developing technical and analytical skills, collaborating and/or managing people, planning, writing papers, developing projects, etc. But it is important to remember that all these skills are transferable and valuable outside academia.

According to statistics, most ECRs will leave the galaxy of academia, but we can still rotate around it as satellites: data collection and management, logistics for expeditions, scientific journalism, teaching, and the list goes on and on. Leaving academia does not automatically imply leaving science. Opportunities exist in industry, government organizations, consultancy firms and areas like scientific management, communication and education. Possibilities are plentiful, but how do we approach them?

We all have mentors in academia who advise us about the right choices for an academic career. But we also need role models from outside academia. We have not received many insights from predecessors who have already left academia, but we now have the possibility to step in and provide assistance to the future generation. We, i.e. the current generation of ECRs, need to become the academic and non-academic mentors of the next generation of scientists. Those leaving academia within the next years - voluntarily or not - should leave a note about their future whereabouts and not "vanish" from the scene. This could be achieved by gathering a list of successful alternative career paths (e.g. on the PAGES website), by organizing seminars and webinars, structured mentoring programs at universities or even blogging.

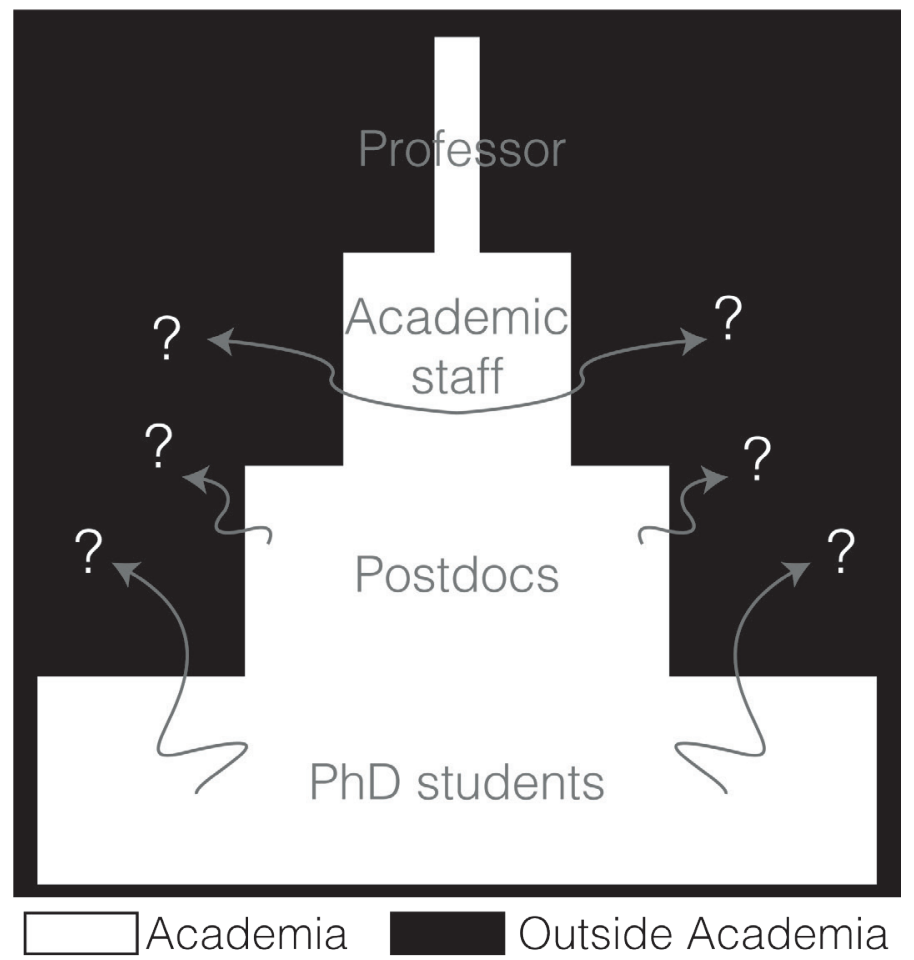

Figure 1: Sketch of the mental representation most ECRs have about their career path.
Light needs to be shed on the dark areas represented in Figure 1. Having access to this critical information should reduce some pressure from ECRs to aim for academic careers and assist them with finding their own way. This could and should be one of the aims of the planned ECR working group, and the next YSM in 2021 would provide the perfect opportunity to evaluate our progress.

\section{AFFILIATIONS}

'Alfred Wegener Institute, Helmholtz Centre for Polar and Marine Science, Potsdam, Germany

Institute for Earth and Environmental Science, University of Potsdam, Germany

Institute of Earth Surface Dynamics, University of Lausanne, Switzerland

${ }^{4}$ Senckenberg Research Institute and Natural History Museum, Research Station of Quaternary Palaeontology, Weimar, Germany

Institute for Systematic Botany, Friedrich Schiller University Jena, Germany

${ }^{6}$ School of Geography, Archaeology and Environmental Studies, University of the Witwatersrand, Johannesburg, South Africa

\section{CONTACT}

Liv Heinecke: Liv.Heinecke@awi.de 